\title{
Catalytic Hydrogenation of Furfural in Alcoholic Media
}

\author{
Irina L. Simakova ${ }^{a}$, \\ Valery E. Tarabanko ${ }^{* b, c}$, Mikhail Yu. Chernyak ${ }^{b}$, \\ Alexander A. Kondrasenko ${ }^{b}$ and Mikhail N. Simonov ${ }^{a}$ \\ ${ }^{a}$ Boreskov Institute of Catalysis \\ 5 pr. Lavrentieva, Novosibirsk, 630090, Russia \\ ${ }^{b}$ Institute of Chemistry and Chemical Technology SB RAS \\ 50/24 Akademgorodok, Krasnoyarsk, 660036, Russia \\ ${ }^{c}$ Siberian Federal University \\ 79 Svobodny, Krasnoyarsk, 660041, Russia
}

Received 01.04.2015, received in revised form 18.10.2015, accepted 02.11.2015

The processes of furfural hydrogenation in the alcohol solutions over copper-ruthenium and platinum catalysts were studied. The equilibrium of acetals formation is shown to establish in the solutions. Both substances, furfural and the acetals of furfural are hydrogenated in the system. The acetals hydrogenation produces alkylfurfuryl ethers, and selectivity of their formation attains 30 and $60 \%$ over platinum and copper-ruthenium catalysts, correspondingly. Furfuryl alcohol and 2-methylfuran are formed among other products. Tetrahydrofuran analogues of the furfural acetals, furfuryl alcohol, and 2-methylfuran are also formed over the platinum catalysts.

Keywords: furfural, propanol, butanol, furfural acetals, propylfurfuryl ether, 2-butoxymethylfuran, hydrogenation, catalysis, copper-ruthenium catalysts, platinum catalysts, biofuels.

DOI: $10.17516 / 1998-2836-2015-8-4-482-490$.

(c) Siberian Federal University. All rights reserved

* Corresponding author E-mail address: veta@icct.ru 


\title{
Каталитическое гидрирование фурфурола \\ в спиртовых средах
}

\author{
И.Л. Симакова ${ }^{a}$, В.Е. Тарабанько ${ }^{\tilde{\beta}, \mathrm{s}}$ \\ М.Ю. Черняк ${ }^{\sigma}$, А.А. Кондрасенко ${ }^{\sigma}$, М.Н. Симонов ${ }^{a}$ \\ ${ }^{a}$ Институт катализа им. Г.К. Борескова СО РАН \\ Россия, 630090, Новосибирск, пр. Ак. Лаврентьева, 5 \\ ${ }^{6}$ Институт химии и химической технологии СО РАН \\ Россия, 660036, Красноярск, Академгородок, 50/24 \\ ${ }^{8}$ Сибирский федеральный университет \\ Россия, 660041, Красноярск, пр. Свободный, 79
}

Изучен прочесс гидрирования фурфурола в спиртовых средах на медно-рутениевых и платиновых катализаторах. Показано, что в растворах устанавливается равновесие фурфурол - ацеталь фурфурола, и гидрируются оба эти вещества. Гидрогенолиз ацеталей дает алкилфурфуриловые эфиры с селективностью до 30 и 60 \% на платиновых и меднорутениевых катализаторах соответственно. Среди других продуктов образуются фурфуриловый спирт и 2-метилфуран. На платиновых катализаторах образуются также тетрагидрофурановые аналоги ацеталей, фурфурилового спирта и 2-метилфурана.

Ключевые слова: фурфурол, пропанол, бутанол, ацетали фурфурола, пропилфурфуриловый эфир, 2-бутоксиметилфуран, гидрирование, катализ, медно-рутениевые катализаторы, платиновые катализаторы, биотоплива.

\section{Введение}

Переработка возобновляемого растительного сырья в биотоплива - интенсивно развивающаяся область химических и биотехнологических исследований, фундамент химических технологий будущего. Продукты такого типа получают либо биохимическими методами (этанол, бутанол и др.), либо химическими (продукты пиролиза, гидролиза и др.). Кислотнокаталитические процессы превращения гексозных углеводов характеризуются сравнительно большими скоростями по сравнению с ферментативными и узким набором продуктов (в основном, 5-гидроксиметилфурфурол и левулиновая (4-кетопентановая) кислота и их эфиры $[1,2])$. Узкий набор продуктов выгодно отличает процессы гидролиза от пиролитических технологий. Каталитическим гидрированием названных продуктов и их эфиров получают перспективные добавки к бензинам $(2,5$-диметилфуран, октановое число 119$)[3,4]$ и дизельным топливам (бутиллевулинат, бутилвалероат).

Биотоплива на основе фурфурола, весьма доступного продукта кислотно-каталитической конверсии пентозных углеводов, только начинают разрабатываться в России, в то время как за рубежом уже ведутся интенсивные разработки $[3,5,6]$. Следует отметить, что сельхозотходы травянистых растений, из которых получение фурфурола наиболее эффективно, могут быть

$$
-483-
$$


дешевле древесных отходов, из которых можно получать 5-гидроксиметилфурфурол [7]. Один из наиболее перспективных продуктов гидрирования фурфурола, 2-метилфуран (ОЧ 131), в смеси с бензином успешно прошел дорожные испытания (90000 км) [3]. Высоким октановым числом (134) характеризуется фурфуриловый спирт [8].

Показана возможность синтеза 2-этоксиметилфурана (этилфурфуриловый эфир) с выходом 30 - 50 \% прямым алкилированием фурфурилового спирта под действием цеолитного и сернокислотного катализаторов и определено его октановое число (ОЧ = 110) [5]. Оценены октановые числа бутилфурфурилового и пропилфурфурилового эфиров - 98 и 113 соответственно [9]. Следует отметить одно преимущество алкилфурфуриловых эфиров по сравнению с метилфуранами - вдвое меньший стехиометрический расход водорода при их получении из фурфурола. Существующие методы получения алкилфурфуриловых эфиров, однако, либо крайне дороги и трудоемки $[10,11]$, либо низкоселективны: кислотно-каталитическое алкилирование фурфурилового спирта этанолом протекает с выходом 30 - 50 \% [5]. Последнее обусловлено протеканием хорошо известных побочных кислотно-каталитических процессов осмоления фурфурилового спирта и его конверсии в левулиновую кислоту. Эти специфические ограничения возможностей алкилирования фурфурилового спирта требуют поиска других методов получения алкилфурфуриловых эфиров.

Одна из возможностей синтеза алкилфурфуриловых эфиров состоит в гидрировании соответствующих ацеталей фурфурола. Гидрирование ацеталей в простые эфиры в литературе рассматривается редко по двум причинам. Во-первых, ацетальная группировка весьма инертна и используется для защиты карбонильной группы в процессах гидрирования других частей сложных молекул. Во-вторых, в подавляющем большинстве случаев, за редкими исключениями типа фурфурилового спирта, простые эфиры легко синтезируются прямым алкилированием. Этилбензиловый эфир образуется в качестве промежуточного продукта гидрирования диэтилацеталя бензальдегида на сульфидированных алюмокобальтмолибденовых катализатоpax [12]. Гидрирование ацеталей 5-хлорметилфурфурола в 2,5-диметилфуран изучено в [13]. Установлено, что гидрирование 5-бутоксиметилфурфурола в бутаноле сопровождается образованием ацеталя, а в качестве продуктов процесса зарегистрированы 2,5-дибутоксиметилфуран и 2,5-дибутоксиметилтетрагидрофуран, продукты гидрогенолиза дибутилацеталя 5-бутоксиметилфурфурола [14, 15].

Цель настоящей работы - исследование процесса каталитического гидрирования фурфурола в спиртовых средах.

\section{Экспериментальная часть}

В работе использовали фурфурол (98 \% основного вещества, Acros Organics), этанолректификат, бутанол и пропанол квалификации ХЧ без дополнительной очистки.

Синтез катализаторов гидрирования. Медно-рутениевые катализаторы получали нанесением активных компонентов на углеродный мезопористый носитель Сибунит $\left(\mathrm{S}_{\mathrm{yд}}=355 \mathrm{~m}^{2} / \Gamma\right)$ [13]. Синтез биметаллического катализатора $8 \% \mathrm{CuRu}(3: 1)$ с атомным соотношением металлов медь/рутений $=3: 1$ проводили совместным нанесением 0,2 $\mathrm{M} \mathrm{RuCl}_{3}$ и 0,5 $\mathrm{M} \mathrm{Cu}\left(\mathrm{NO}_{3}\right)_{2}$ водных растворов пропиткой по влагоемкости углеродного носителя. Высушенные катализаторы восстанавливали водородом в течение 6 ч, поднимая температуру до $360^{\circ} \mathrm{C}$ со скоростью $2 \mathrm{~K} / \mathrm{Mин}$. 
Катализатор перед выгрузкой из реактора пассивировали газообразным азотом, содержащим $\sim 0,002$ вес. \% кислорода.

Платиновый катализатор $3 \% \mathrm{Pt} / \mathrm{C}$ синтезировали методом пропитки углеродного носителя Сибунита раствором $\mathrm{H}_{2} \mathrm{PtCl}_{6}$ с последующим восстановлением до металлической платины в токе водорода при нагревании до температуры $350{ }^{\circ} \mathrm{C}$ со скоростью нагрева 1,5 К/мин [15]. Модифицированные платиновые катализаторы синтезировали аналогично методом совместной пропитки углеродного носителя Сибунит раствором $\mathrm{H}_{2} \mathrm{PtCl}_{6}$ с растворами $\mathrm{RuCl}_{3}, \mathrm{CoCl}_{2}, \mathrm{NiCl}_{2}$ и $\mathrm{HReO}_{4}$ соответственно с последующим восстановлением в токе водорода при нагревании до температуры $350{ }^{\circ} \mathrm{C}$ со скоростью нагрева $1,5 \mathrm{~K} / \mathrm{мин.}$

Физико-химические методы анализа. Определение процентного содержания металла на углеродном носителе проводили рентгеноспектральным методом на флуоресцентном анализаторе VRA-30 с Cr-анодом рентгеновской трубки.

Спектры РФЭС были записаны на фотоэлектронном спектрометре SPECS с использованием немонохроматизированного излучения $\mathrm{AlK}=1486,61$ эВ, 205 Вт. Шкала энергий связи $\left(\mathrm{E}_{\mathrm{cв}}\right)$ была предварительно откалибрована по положению пиков основных уровней металлического золота и меди: Au4f7/2 (84,0 эB) и $\mathrm{Cu} 2 \mathrm{p} 3 / 2$ (932,67 эВ). Эффект подзарядки, возникающий в процессе фотоэмиссии электронов, учитывался с помощью метода внутреннего стандарта, в качестве которого использовали линию C1s (284,5 эB) углерода (Сибунит). Обзорные спектры записывали при энергии пропускания анализатора - 50 эВ, отдельные спектральные районы 10 и 20 эВ.

Анализ методом ПЭМВР проводили на просвечивающем электронном микроскопе высокого разрешения «ЈЕМ-2010» (Япония) с разрешением по решетке 0,14 нм и ускоряющим напряжением 200 кВ. Средний диаметр частиц (не менее 250 частиц) рассчитывали по следующей формуле:

$$
d_{m}=\frac{\sum_{i}\left(x_{i} d_{i}\right)}{\sum_{i} x_{i}},
$$

где $x_{i}$ - число частиц с диаметром $d_{i}$.

Элементный анализ поверхности образцов (EDX) проводили с энергодисперсионным рентгеновским детектором «EDAX DX-4» фирмы Ametek Inc., США. Площадь анализируемой поверхности составляла 150-300 нм².

Гидрирование фурфурола. Эксперименты по жидкофазному гидрированию фурфурола в спиртах проводили в автоклаве (150 мл) из нержавеющей стали с перемешиванием под давлением водорода 10 атм при $200{ }^{\circ} \mathrm{C}$ с автоматическим контролем за объемом поглощенного газа. Загрузка спирта - 19,2 г, фурфурола - 0,53 г. Масса катализатора и продолжительность эксперимента указаны далее по тексту.

Идентификацию конденсированных продуктов проводили методом хроматомассспектроскопии на приборах VG-7070 GC/MS (колонка 30 м х 0.2 мм Silicone SE-30) и Agilent $5973 \mathrm{~N}$ EI/PCI (колонка 30мм х 0,25мм HР-5ms). Количественный анализ реакционных смесей проводили методом газожидкостной хроматографии на хроматографе ЛХМ-80 (НПО «Агроприбор») с пламенно-ионизационным детектором и кварцевой насадочной колонкой 2,0 м×2,0

$$
-485-
$$


мм, заполненной сорбентом Chromosorb 101, модифицированным 5 \% FFAP. Газ-носитель азот. Обработка хроматограмм производилась с помощью пакета программ «Гепард». Калибровку проводили по образцам веществ, за исключением ацеталей тетрагидрофурфурола, для которого калибровочные коэффициенты принимались равными таковым для соответствующих ацеталей фурфурола.

\section{Результаты и обсуждение}

Согласно данным просвечивающей электронной микроскопии высокого разрешения, катализаторы $\mathrm{Pt} / \mathrm{C}, \mathrm{PtRe} / \mathrm{C}, \mathrm{PtRu} / \mathrm{C}, \mathrm{PtNi} / \mathrm{C}$ и $\mathrm{PtCo} / \mathrm{C}$ представляют собой нанодисперсные частицы активного металла сферической формы, равномерно распределенные по поверхности углеродного носителя. Средний размер частиц активного компонента образцов $\mathrm{Pt} / \mathrm{C}-1,3$ нм, $\mathrm{PtRe} / \mathrm{C}-1,2$ нм, PtRu/C 1,3 нм, PtNi/C - 1,9 нм и $\mathrm{PtCo} / \mathrm{C}-1,3$ нм (рис. 1-4). С учетом примерно одинакового содержания металла, что подтверждают данные рентгенофлуоресцентного метода анализа, удельные поверхности активного компонента в навесках катализаторов одинаковой массы имеют сопоставимые значения.

При сопоставлении данных РФЭС об электронном состоянии активного компонента в катализаторах было установлено, что активный компонент представляет собой металлические частицы с незначительной долей окисленного металла $\mathrm{Ni}$ и Со в образцах $\mathrm{PtNi} / \mathrm{C}$ и $\mathrm{PtCo} / \mathrm{C}$, которые, возможно, претерпевают определенные изменения в условиях реакции.

В табл. 1 отражены результаты гидрирования фурфурола в пропаноле и бутаноле на медно-рутениевом катализаторе. Медные катализаторы используются для гидрирования кар-

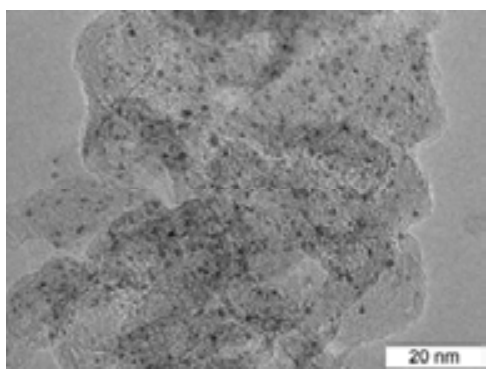

Рис. 1. Микрофотография катализатора $\mathrm{Pt} / \mathrm{C}$

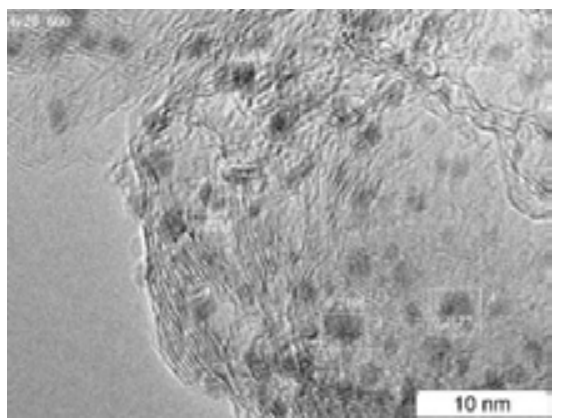

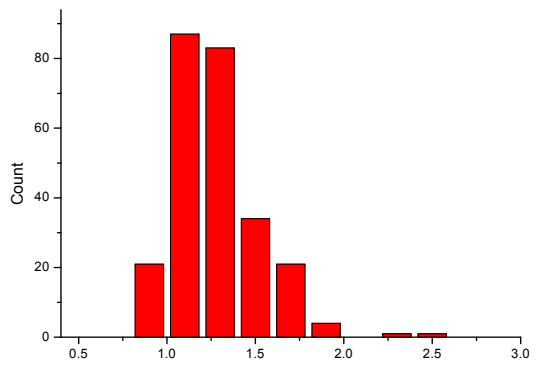

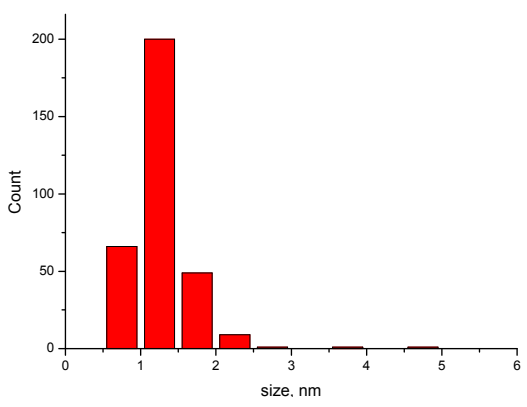

Рис. 2. Микрофотография катализатора $\mathrm{PtRu} / \mathrm{C}(3 \%+3$ \%) 

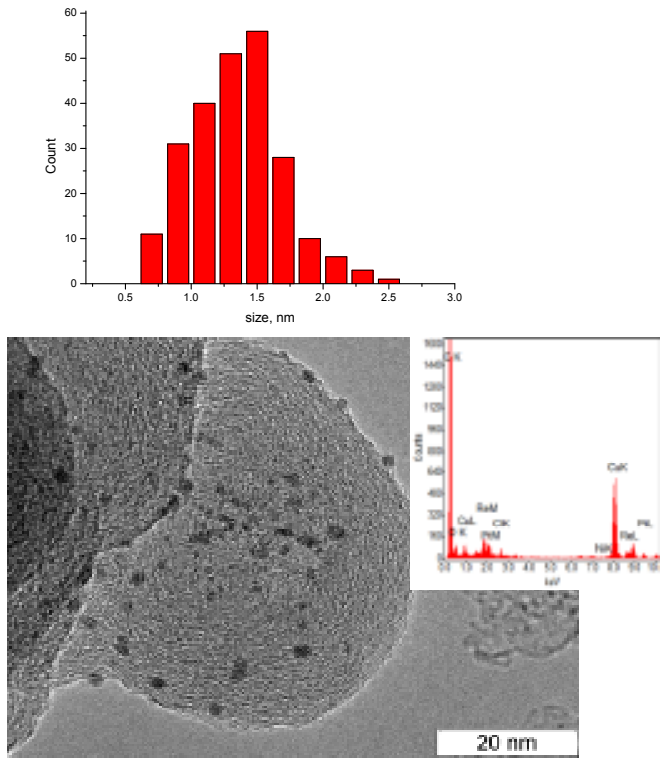
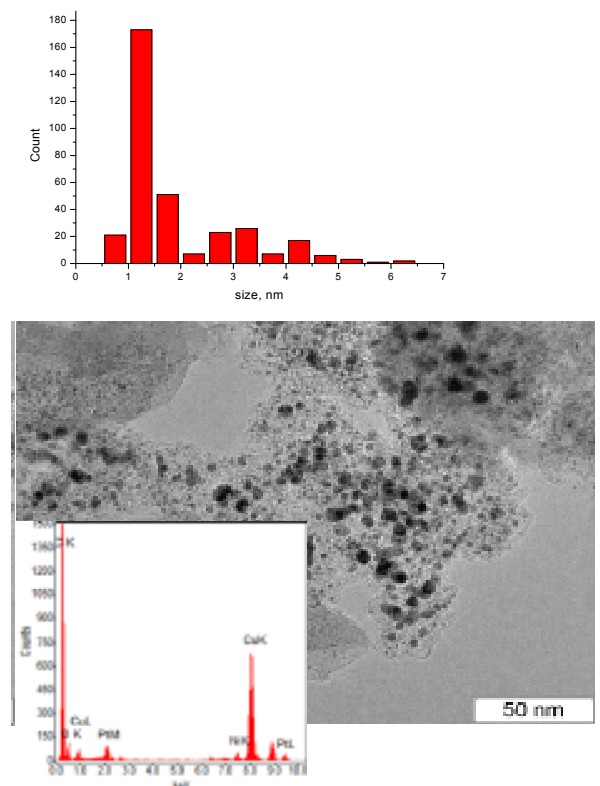

Рис. 3. Микрофотография катализатора $8 \mathrm{PtRe} / \mathrm{C}$ (1:3) (слева) и $\mathrm{PtNi} / \mathrm{C}(3$ \%+3 \%) (справа)
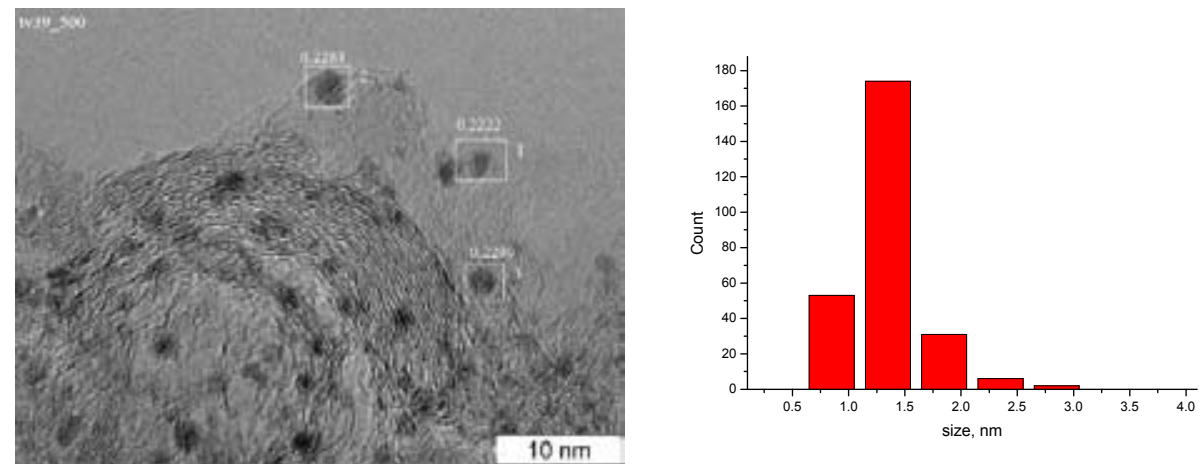

Рис. 4. Микрофотография катализатора $\mathrm{PtCo} / \mathrm{C}(3 \%+3 \%)$

бонильной группы фурфурола и не активны в гидрировании фуранового кольца, а аналогичный медно-рутениевый катализатор использован для гидрирования 5-гидроксиметилфурфурола в 2,5-диметилфуран [3].

Представленные результаты показывают, что в отсутствие водорода система вполне стабильна в условиях процесса и за исключением равновесного образования ацеталей других продуктов в растворе не образуется. Доля ацеталей в продуктах может превышать $60-70$ мол. \%. В присутствии медно-рутениевого катализатора продукты гидрирования кольца в системе практически не образуются. Максимальные выходы пропил- и бутилфурфурилового эфиров близки между собой и составляют 9,5 и 8,5 мол. \% соответственно. Селективность процесса по этим продуктам, учитывая небольшую конверсию фурфурола и его ацеталя в продукты 
Таблица 1. Влияние условий реакции на выход продуктов гидрирования фурфурола в спиртах на катализаторе $8 \% \mathrm{CuRu/C}$. Условия процесса: 0,53 г (5,53 ммоль) фурфурола, 19,2 г спирта, 400 мг катализатора, парциальное давление водорода 1,0 МПа

\begin{tabular}{|c|c|c|c|c|c|c|c|c|c|}
\hline \multirow[b]{2}{*}{ №№ } & \multirow[b]{2}{*}{$\begin{array}{c}\text { Температура, } \\
{ }^{\circ} \mathrm{C}\end{array}$} & \multirow[b]{2}{*}{$\begin{array}{c}\text { Давление } \\
\mathrm{H}_{2}, \mathrm{MPa}\end{array}$} & \multirow[b]{2}{*}{$\begin{array}{c}\text { Время } \\
\text { реакции, } \\
\text { мин }\end{array}$} & \multirow[b]{2}{*}{ Спирт } & \multicolumn{5}{|c|}{ Состав продуктов, ммоль } \\
\hline & & & & & $\begin{array}{l}5 \\
\sum_{0}^{2} \\
\text { 离 } \\
\sum_{0}^{2}\end{array}$ & 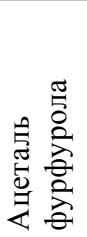 & 空 & 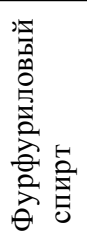 & 鴶 \\
\hline $13^{\mathrm{a}}$ & 110 & 0 & 360 & бутанол & 2.37 & 2.99 & - & - & \\
\hline $3^{\mathrm{a}}$ & 110 & 1,0 & 375 & бутанол & 3,63 & 0.74 & $0.47 / 41$ & 0.61 & 0.02 \\
\hline $4^{a}$ & 150 & 1,0 & 420 & бутанол & 3.11 & 0.63 & $0.49 / 27$ & 1,00 & 0.04 \\
\hline $5^{\mathrm{a}}$ & 200 & 1,0 & 360 & бутанол & 1.94 & 0.31 & $0.40 / 12$ & 2.62 & 0.02 \\
\hline 6 & 110 & 1,0 & 360 & пропанол & 1.47 & 3.21 & $0.52 / 62$ & 0.46 & 0.13 \\
\hline 7 & 150 & 1,0 & 150 & пропанол & 1.08 & 2.56 & $0.39 / 21$ & 0.24 & 0.18 \\
\hline 8 & 200 & 1,0 & 360 & пропанол & 1.33 & 2.18 & $0.30 / 15$ & 0.77 & 0.18 \\
\hline 16 & 110 & 2,0 & 360 & пропанол & 0.95 & 1.85 & $0.30 / 11$ & 0.29 & 0.09 \\
\hline 17 & 110 & 3,0 & 360 & пропанол & 0.78 & 1.59 & $0.31 / 10$ & 0.45 & 0.12 \\
\hline
\end{tabular}

Примечания: а - загрузка катализатора 200 мг; б - указаны выходы и селективность, ммоль/ селективность, \%.

гидрирования (15 - 21 \%), достигает 62 и 41 \% для пропил- и бутилфурфурилового эфиров соответственно.

Селективность процесса по пропил- и бутилфурфуриловому эфирам снижается с ростом температуры в основном за счет образования фурфурилового спирта. Увеличение давления водорода в реакторе также ведет к снижению выхода пропилфурфурилового эфира и селективности его образования. Среди других продуктов образуется 2-метилфуран (до 4 мол. \%).

На более активных платиновых катализаторах, за исключением платино-рениевых, наблюдается полная конверсия фурфурола (табл. 2). Выход пропилфурфурилового эфира на платиновых катализаторах в основном находится на уровне 15 - $19 \%$, а максимальная селективность достигается на трехпроцентном платино-рениевом катализаторе (30 \%). Гидрирование фурфурилового спирта в пропаноле в этих условиях дает 5 \% пропилфурфурилового эфира (селективность около 7 \%). Это означает, что алкилфурфуриловые эфиры в системе фурфурол спирт образуются преимущественно путем гидрогенолиза ацеталей, а не через алкилирование образующегося фурфурилового спирта (рис. 5).

В качестве побочных продуктов гидрирования образуются 2-метилфуран (до 30 мол. \%) и фурфуриловый спирт (до 35 мол. \%). Наблюдаются также продукты гидрирования фуранового кольца, в первую очередь на платино-рутениевом катализаторе (тетрагидрофурфуриловый спирт, 2-метилтетрагидрофуран и др.).

Таким образом, результаты экспериментов показывают, что гидрирование фурфурола в спиртовых средах позволяет получать алкилфурфуриловые эфиры с селективностью вплоть до 
Таблица 2. Влияние условий на выход продуктов гидрирования фурфурола в пропаноле на платиновых катализаторах. Условия процесса: 5,53 ммоль фурфурола, 19,2 г спирта, 400 мг катализатора, $110{ }^{\circ} \mathrm{C}$, парциальное давление водорода 1,0 МПа, продолжительность процесса 6 ч

\begin{tabular}{|c|c|c|c|c|c|c|c|}
\hline \multirow[b]{2}{*}{ № } & \multirow[b]{2}{*}{ Катализатор } & \multicolumn{6}{|c|}{ Состав продуктов, ммоль } \\
\hline & & 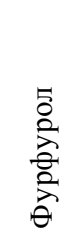 & 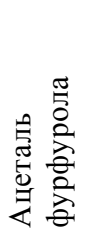 & 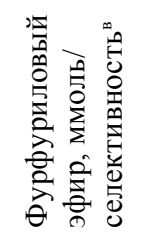 & 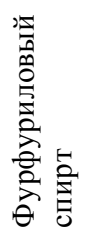 & 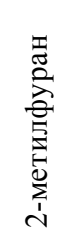 & 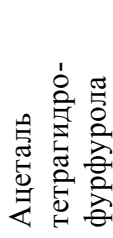 \\
\hline $18^{\mathrm{a}}$ & $3 \% \mathrm{Pt} / \mathrm{C}$ & - & 0.85 & $0.90 / 0.19$ & 0.48 & 0.61 & 0.104 \\
\hline $19^{\mathrm{a}}$ & $\mathrm{PtRu} / \mathrm{C}(3 \%+3 \%)$ & - & - & $0,75 / 0.14$ & - & - & - \\
\hline $20^{\mathrm{a}}$ & $\mathrm{PtNi} / \mathrm{C}(3 \%+3 \%)$ & - & 0.17 & $1.04 / 0.19$ & 1.67 & 0.58 & 0.33 \\
\hline 21 & $\mathrm{PtCo} / \mathrm{C}(3 \%+3 \%)$ & - & - & $0.36 / 0.065$ & 1.90 & 0.78 & 0.26 \\
\hline 22 & $6 \% \mathrm{PtRe} / \mathrm{C}(1: 1)$ & - & - & $0.88 / 0.30$ & 1.13 & 1.77 & 0.21 \\
\hline $23^{a}$ & $8 \%$ PtRe $(1: 3)$ & 0.54 & 2.75 & $0.56 / 0.20$ & 0.96 & 0.64 & - \\
\hline $24^{\mathrm{a}, 6}$ & $8 \% \operatorname{PtRe}(1: 3)$ & - & - & $0.28 / 0.067$ & $1.36^{\mathrm{r}}$ & 3.00 & - \\
\hline
\end{tabular}

Примечания: а - загрузка катализатора 200 мг; б - эксперимент с фурфуриловым спиртом вместо фурфурола; в - указаны выходы (ммоль) и селективность в долях единицы; г - идентифицирован также тетрагидрофурфуриловый спирт 0,6 ммоль.

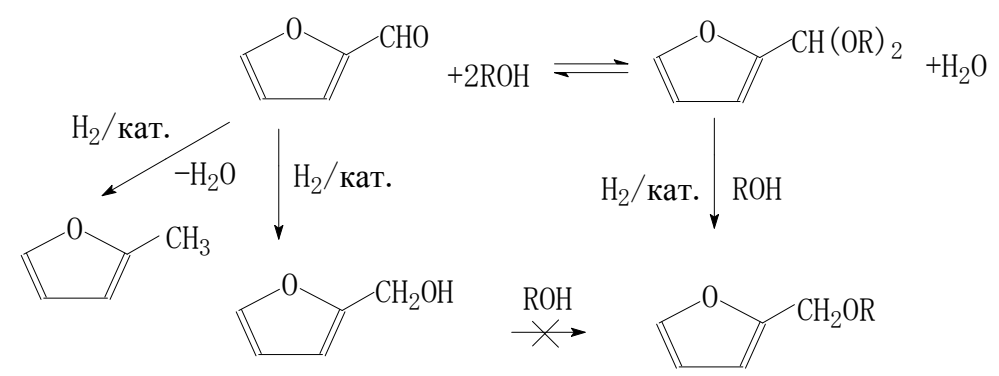

Рис. 5. Маршруты превращения фурфурола в условиях каталитического гидрирования молекулярным водородом в присутствии спиртов

60 \%. Это открывает возможности создания гидрогенизационных процессов получения высокооктановых компонентов бензинов из возобновляемого растительного сырья с вдвое меньшим расходом водорода по сравнению с получением 2-метилфурана. Важно отметить, что наряду с хорошими смазывающими свойствами и низкой температурой застывания алкилфурфуриловых эфиров наличие в их составе кислорода позволяет значительно улучшить экологические показатели двигателей, работающих на этих альтернативных моторных топливах, уменьшая вредные выбросы при сгорании моторных топлив.

Авторы признательны Российскому фонду фундаментальных исследований за финансовую поддержку работы, грант № 13-03-00754. 


\section{Список литературы}

1. Тарабанько В.Е., Черняк М.Ю., Кузнецов Б.Н., Захарова О.В. Исследование процессов кислотно-каталитической дегидратации углеводов в присутствии бутанола при умеренных температурах. Химия растительного сырья 2002. № 2. С. 5 - 15.

2. Tarabanko V.E., Smirnova M.A., Chernyak M.Yu., Kondrasenko A.A., Tarabanko N.V. The Nature and Mechanism of Selectivity Decrease of the Acid-catalyzed Fructose Conversion with Increasing the Carbohydrate Concentration. Journal of Siberian Federal University, Chemistry 2015. Vol. 8(1). P. 6-18. (In Russ.)

3. Roman-Leshkov Y., Barret C.J., Liu Z.Y., Dumesic J.A. Production of Dimethylfuran for Liquid Fuels from Biomass-derived Carbohydrate. Nature 2007. Vol. 447, P. 982-986.

4. Alonso D.M., Bond J.Q., Dumesic J.A. Catalytic conversion of biomass to biofuels. Green Chem. 2010. Vol. 12. P. 1493-1513.

5. Lange J.-P., Evert van der Heide, Jeroen van Buijtenen, Price R. Furfural - A Promising Platform for Lignocellulosic Biofuels. ChemSusChem 2012. Vol. 5. C. 150 - 166.

6. Максимов А.Л., Нехаев А.И., Рамазанов Д.Н. Простые эфиры и ацетали - перспективные продукты нефтехимии из возобновляемого сырья (обзор). Нефтехимия 2015. Т. 55(1). C. 3-24.

7. Варфоломеев С.Д., Моисеев И.И., Мясоедов Б.Ф. Энергоносители из возобновляемого сырья. Химические аспекты. Вестник РАН 2009. Т. 79 (7), С. 595- 604

8. Resasco D.E., Sitthisa S., Faria J., Prasomsri T., Ruiz M.P. 5. Furfurals as chemical platform for biofuels production. In: Heterogeneous catalysis in biomass to chemicals and fuels. Ed. Kubicka D., Kubicková I. Research Signpost, India, 2011.

9. Тарабанько В.Е., Черняк М.Ю., Морозов А.А., Кайгородов К.Л., Безбородов Ю.Н., Орловская Н.Ф., Надейкин И.В. Новые высокооктановые компоненты бензинов из растительного сырья. Журнал СФУ. Химия 2014. Т. 7(1). С. 31-35.

10. L. von Wissell, Tollens B. XXXIII. Ueber den Furfur- oder Furalkohol und einige Derivate desselben. Justus Liebigs Annalen der Chemie 1893. Vol. 272(3), Р. 291-306.

11. Потапов В.М. Органикум. Практикум по органической химии. Т.2 М.: Мир, 1979. $64 \mathrm{c}$.

12. Moreau C., Lecomte J., Mseddi S., Zmimita N. Stereoelectronic effects in hydrolysis and hydrogenolysis of acetals and thioacetals in the presence of heterogeneous catalysts. Journal of molecular catalysis A-Chemical 1997. Vol. 125(2-3). P. 143-149.

13. Dutta S., Mascal M. Novel Pathways to 2,5-Dimethylfuran via Biomass-Derived 5-(Chloromethyl) furfural. ChemSusChem 2014. Vol. 7(11). P. 3028-3030.

14. Симакова И.Л., Тарабанько В.Е., Морозов А.А., Черняк М.Ю. Каталитическое гидрирование 5-бутоксиметилфурфурола на медьсодержащих катализаторах. Южно-сибирский научный вестник 2014. № 3 (7). С. 37-42.

15. Симакова И.Л., Морозов А.А., Тарабанько В.Е., Черняк М.Ю. Каталитическое гидрирование 5-бутоксиметилфурфурола на палладиевых катализаторах. Журнал СФУ. Химия 2014. T. 7(4). C. 536-545. 